\title{
LA EVALUACIÓN DE LAS FUNCIONES DOCENTES EN LOS PROYECTOS DE ACCIÓN SOCIAL DE LA UNIVERSIDAD DE COSTA RICA: ANÁLISIS Y PROPUESTA DE ACTUALIZACIÓN THE EVALUATION OF PROFESSORIATE'S FUNCTIONS IN SOCIAL ACTION PROJECTS OF THE UNIVERSITY OF COSTA RICA: AN ANALYSIS AND NEW PROPOSAL
}

\section{Volumen 14, Número 3 \\ Setiembre - Diciembre}

pp. 1-31

Este número se publicó el 30 de setiembre de 2014

Yensi Vargas Sandoval

Revista indizada en REDALYC, SCIELO

Revista distribuida en las bases de datos:

CATÁLOGO DE LATINDEX, IRESIE, CLASE, DIALNET, DOAJ, E-REVIST@S, SHERPA/ROMEO, QUALIS, MIAR

Revista registrada en los directorios:

ULRICH'S, REDIE, RINACE, OEI, MAESTROTECA, PREAL, $\underline{\text { CLACSO }}$ 


\title{
LA EVALUACIÓN DE LAS FUNCIONES DOCENTES EN LOS PROYECTOS DE ACCIÓN SOCIAL DE LA UNIVERSIDAD DE COSTA RICA: ANÁLISIS Y PROPUESTA DE ACTUALIZACIÓN THE EVALUATION OF PROFESSORIATE'S FUNCTIONS IN SOCIAL ACTION PROJECTS OF THE UNIVERSITY OF COSTA RICA: AN ANALYSIS AND NEW PROPOSAL
}

\author{
Yensi Vargas Sandoval ${ }^{1}$
}

\begin{abstract}
Resumen: El presente artículo documenta la investigación desarrollada en la Vicerrectoría de Acción Social de la Universidad de Costa Rica, en que se revisan los criterios para evaluar las funciones docentes en los proyectos de acción social. La estrategia metodológica incluyó estudio y análisis documental, grupos de discusión para elaborar criterios y parámetros, así como los esfuerzos de triangular la información y validar la propuesta. En los primeros apartados se describe el marco institucional y normativo de la acción social universitaria, que contextualiza la propuesta para actualizar el instrumento vigente utilizado en la Vicerrectoría de Acción Social. Dicha propuesta incluye la fundamentación de los ejes principales, los criterios, parámetros y evidencias requeridas para calificar el desempeño docente en la actividad de acción social. Desde la perspectiva de la evaluación cualitativa, se concluye la necesidad de modificar la lógica evaluativa como mecanismo de control, y propiciar un ejercicio valorativo constante que mejore y promueva los logros, que recopile los aprendizajes y potencie los esfuerzos del vínculo universidad-sociedad. La nueva propuesta es un insumo para una labor que se sugiere que sea liderada por la Vicerrectoría de Acción Social.
\end{abstract}

Palabras clave: EVALUACIÓN DE LA ACCIÓN SOCIAL, EDUCACIÓN SUPERIOR, REGLAMENTO DE RÉGIMEN ACADÉMICO Y SERVICIO DOCENTE, UNIVERSIDAD DE COSTA RICA, VICERRECTORÍA DE ACCIÓN SOCIAL, COSTA RICA.

\begin{abstract}
This paper presents the results of an evaluation research conducted at the Vicerrectoría de Acción Social of the University of Costa Rica, to analyze the criteria on which is based the assessment of the professoriate's functions related to social action projects. The methodological strategy included techniques such as documentary analysis and discussion groups to elaborate alternative criteria and parameters, as well as the efforts to triangulate and validate the proposal. The first sections deal with the institutional and legal framework of the university's social action, which circumscribes the context of the proposal to update the instrument currently used by the Vicerrectoría de Acción Social. The new proposal includes the theoretical and legal premises of the core themes, the criteria, parameters and required evidence to qualify the professoriate's performance in social action's activities. From the perspective of qualitative evaluation, we stress the need for overcoming the evaluative logic viewed simply as a control mechanism, to foster a permanent evaluative practice to improve and promote the achievements, to gather knowledge and strengthen the UniversitySociety's link. This new proposal represents a contribution to a work that should be leaded by the Vicerrectoría de Acción Social.
\end{abstract}

Keywords: SOCIAL ACTION EVALUATION, HIGHER EDUCATION, CODE OF REGIMEN ACADÉMICO AND SERVICIO DOCENTE, UNIVERSITY OF COSTA RICA, VICERRECTORÍA DE ACCIÓN SOCIAL, COSTA $R I C A$.

\footnotetext{
1 Investigadora de la Universidad de Costa Rica, en el Instituto de Investigación en Educación y en la Escuela de Sociología de la Universidad Nacional de Costa Rica.
}

Dirección electrónica: YENSI.VARGAS@ucr.ac.cr

Artículo recibido:23 de abril, 2014

Enviado para corrección: 30 de junio, 2014

Aprobado: 31 de julio, 2014 


\section{Introducción ${ }^{2}$}

La Universidad de Costa Rica posee un sistema de calificación del personal docente según sus méritos académicos, conocido como Régimen Académico Docente. Las regulaciones principales para dicho régimen están contenidas en una normativa de carácter general denominada Reglamento de Régimen Académico y Servicio Docente (RRASD), cuya aprobación data de $1982^{3}$.

Este Reglamento de alcance general e institucional ordena lo relacionado con el ingreso de profesores y profesoras en propiedad, ${ }^{4}$ así como el conjunto de criterios exigidos para el ascenso y la calificación de la obra académica que se desarrolle como producto de actividades en docencia, investigación y acción social.

Este cuerpo normativo define las categorías que pueden obtener el profesorado universitario según los méritos académicos y la experiencia universitaria. Considera también los procesos de ingreso y los puntajes necesarios para el ascenso en las distintas categorías; estipula el funcionamiento de una comisión de carácter institucional, la cual vigila la calificación de las actividades del personal docente, por ejemplo, desempeño en docencia (grado y posgrado), labores de investigación y acción social, así como el tiempo de servicio, el conocimiento de idiomas, las publicaciones, las obras didácticas y los trabajos académicos.

La Vicerrectoría de Acción Social (VAS) es una de las instancias ejecutivas y de apoyo directo a la Rectoría. Si bien es cierto, es competencia de la Comisión de Régimen Académico revisar y calificar las obras académicas para asignar los puntajes del personal docente, un primer esfuerzo de valoración de las tareas universitarias se realiza en cada Vicerrectoría, según lo establece el artículo 47, inciso ch), del Reglamento de Régimen Académico y Servicio Docente.

El análisis y la formulación de una propuesta para evaluar estas funciones, procede de la revisión del instrumento vigente, que se utiliza para calificar las labores que

\footnotetext{
${ }^{2}$ La síntesis que plantea este artículo proviene de los resultados del estudio evaluativo, con el cual la autora finaliza en 2013 la formación de posgrado en la Maestría en Evaluación de Programas y Proyectos de Desarrollo de la Universidad de Costa Rica, y que se denomina Estudio evaluativo sobre la calificación de la acción social para puntaje en Régimen Académico de la Universidad de Costa Rica: una propuesta de actualización.

${ }^{3}$ Este Reglamento fue aprobado en la sesión № 2869-17, del 16 de febrero de 1982; publicado en La Gaceta Oficial 76-82, del 22 de abril de 1982; De conformidad con la sesión 3228-13 del Consejo Universitario celebrada el 23 de octubre de 1985, se publica en La Gaceta Universitaria 16-85, del 19 de diciembre de 1985. La edición vigente de este Reglamento incluye una modificación parcial aprobada en la sesión N. ${ }^{\circ} 5297-$ 11 , del 14 de octubre de 2008.

${ }^{4}$ La condición de propiedad contraria a la condición de nombramiento interino.
} 
desarrollan en este campo el profesorado universitario. Dicho estudio se desarrolló en la Vicerrectoría de Acción Social mediante un proceso de grupos de discusión con personal que asesora la ejecución de proyectos, lo que permitió plantear la actualización con ejes, criterios y parámetros que la Vicerrectoría podría considerar para incorporarlos al proceso de evaluación de las labores de acción social.

\section{Referentes contextuales y teóricos de la evaluación}

\subsection{Contexto de la acción social universitaria}

Para realizar una referencia del contexto institucional en que se efectúa el estudio evaluativo, es importante ofrecer una idea de la estructura organizativa universitaria establecida en el Estatuto Orgánico de la Universidad de Costa Rica (2001), conformada por áreas académicas ${ }^{5}$ que se componen por facultades, escuelas, institutos y centros de investigación. También se cuenta con sedes, recintos y estaciones experimentales ${ }^{6}$ que desarrollan funciones de docencia, investigación y acción social. Lo anterior, por cuanto es en las unidades académicas y de investigación, desde donde se planifican y ejecutan las iniciativas universitarias de investigación y de acción social.

La Universidad de Costa Rica cuenta con 6 Áreas Académicas definidas en el artículo $70^{7}$ del Estatuto Orgánico: Artes y Letras; Ciencias Básicas, Ciencias Sociales, Ingeniería, Salud, Ciencias Agroalimentarias.

Dichas áreas académicas están compuestas por Facultades, que a su vez se integran por Escuelas, denominadas también en la documentación universitaria como Unidades Académicas. Actualmente existen 9 Facultades integradas por Escuelas y 4 Facultades que no se integran por Escuelas y que desarrollan de igual manera actividades de docencia, investigación y acción social.

${ }^{5}$ Estatuto Orgánico de la Universidad de Costa Rica, capítulo VII Áreas, Título II Estructura y Gobierno.

${ }^{6}$ En el Estatuto Orgánico de la Universidad de Costa Rica, Capítulo IX -Sedes Regionales-, Artículo 108 bis, se señala que las Sedes Regionales son instancias que dependen de la Rectoría y se dirigen a ampliar las oportunidades de realización de la actividad universitaria en las diferentes regiones del país.

7 Estatuto Orgánico de la Universidad de Costa Rica Capítulo VII. ARTíCULO 70.-Las áreas, integradas por Facultades afines, son las siguientes: a) Artes y Letras, integrada por las Facultades de Bellas Artes y Letras. b) Ciencias Básicas, integrada por la Facultad de Ciencias. c) Ciencias Sociales, integrada por las Facultades de Ciencias Económicas, Ciencias Sociales, Derecho y Educación. ch) Ingeniería, integrada por las Facultades de Ingeniería. d) Salud, integrada por las Facultades de Farmacia, Medicina, Microbiología y Odontología. e) Ciencias Agroalimentarias, integrada por la Facultad de Ciencias Agroalimentarias (UCR, 2001, 16). 
La Universidad cuenta también en su estructura organizativa con 29 Centros de Investigación y 12 Institutos, ${ }^{8}$ instancias que desarrollan actividades integradas de investigación y acción social.

La organización administrativa de la Universidad de Costa Rica sigue en crecimiento y en transformación. En 2012, por ejemplo, el Consejo Universitario dictaminó en favor de la creación de 4 nuevas unidades de investigación, ${ }^{9}$ de ahí que la acción social se desenvuelve en un contexto cambiante y dinámico.

En el desarrollo de la acción social intervienen varias instancias: las propuestas formuladas por los docentes provienen de las distintas unidades académicas y las unidades de investigación, las cuales se inscriben, según la modalidad, en alguna de las 3 secciones de la Vicerrectoría, ya sea en la Sección de Trabajo Comunal Universitario, en la Sección de Extensión Docente o en la Sección de Extensión Cultural.

\subsection{Reglamentación referente a las funciones universitarias}

Como se apuntó en líneas anteriores, el Reglamento de Régimen Académico (RRASD) es el conjunto principal de normas que define las categorías que pueden obtener las profesoras y los profesores, según los méritos académicos y la experiencia universitaria. Considera también los procesos de ingreso y los puntajes necesarios para el ascenso en las distintas categorías; estipula el funcionamiento de una comisión de carácter institucional, la cual vigila la calificación de las actividades del personal docente, por ejemplo, desempeño en docencia (grado y posgrado) labores de investigación y acción social, así como el tiempo de servicio, el conocimiento de idiomas, las publicaciones, las obras didácticas, los trabajos académicos; en síntesis la formación, la experiencia, la trayectoria y la producción intelectual.

El Reglamento de Régimen Académico (RRASD) tiene una estrecha relación con el reglamento Regulaciones del Régimen Salarial Académico de la Universidad de Costa Rica (UCR, Consejo Universitario, 1991), el cual contiene las disposiciones para la asignación del salario del personal docente. Este cuerpo normativo establece las

\footnotetext{
8 Universidad de Costa Rica, Vicerrectoría de Investigación: La investigación en la Universidad de Costa Rica. Disponible en www.vinv.ucr.ac.cr

9 En el boletín electrónico Enlaces del Consejo Universitario, se informa que ese Órgano Colegiado aprobó recientemente la creación de 4 nuevas unidades de investigación de la Universidad de Costa Rica (UCR), una de ellas, en la Sede de Occidente. Se trata de los centros de investigaciones en Diversidad Cultural y Estudios Regionales, Neurociencias y Ciencias del Movimiento Humano, así como el Instituto de Investigación en Artes (Enlaces N.․ 50, octubre-noviembre 2012).
} 
disposiciones que rigen la remuneración salarial de las personas contratadas por la Universidad de Costa Rica para realizar tareas académicas, el cual se aprobó en 1991 ( La Gaceta Universitaria N. 5-91, del 19 de agosto de 1991).

Estos conjuntos de normas regulan por una parte el reconocimiento de méritos académicos, y en forma complementaria, la asignación salarial.

\subsection{Procedimientos para valorar el desempeño de la acción social}

Con respecto al procedimiento para obtener calificación por labores de acción social, la persona interesada debe realizar la gestión ante la Comisión de Régimen Académico en las fechas establecidas para tal efecto, con el fin de que esta Comisión solicite el estudio a la Vicerrectoría de Acción Social. Posteriormente, dicha Vicerrectoría atiende la petición de la Comisión de Régimen Académico, pero no la gestión específica de cada persona interesada.

Durante cada ciclo lectivo, la Comisión de Régimen Académico remite a las vicerrectorías el listado del personal académico que solicita la calificación correspondiente. El artículo 47, inciso ch), en su último párrafo, establece: "(...) Cada Vicerrectoría elaborará sus propias normas de evaluación para proceder a asignar estas calificaciones, mediante la aplicación de instrumentos de medición adecuados para cada área".

Del articulado del Reglamento señalado se desprende que la Vicerrectoría de Acción Social debe establecer normas de evaluación para otorgar dichas calificaciones. Además, el puntaje que se asigna en las funciones de acción social conlleva a un eventual ascenso en Régimen Académico; esto representa pasar de una categoría a otra $\mathrm{y}$, por consiguiente, de un salario base a otro.

\subsection{Punto de partida: la utilidad de los procesos de evaluación}

Desde el Consejo Nacional de Rectores (CONARE), se identifica uno de los desafíos para la educación superior universitaria estatal relacionada con el ejercicio de la evaluación que, en términos generales, requieren estas instituciones y que se dirige a: "Convertir los resultados de la evaluación, como instrumento de gestión, en una herramienta útil para hacer más expedita, eficiente y eficaz la toma de decisiones orientada a garantizar la calidad". (CONARE, 2005, p. 27) 
En este enunciado emitido por el CONARE, se identifican algunas de las características importantes de la evaluación como actividad general y como disciplina de conocimiento, entre ellas: que la evaluación tiene resultados aplicables; que se trata de un instrumento de gestión en las organizaciones y, por ende, en las instituciones universitarias. Además, representa una herramienta útil para la toma de decisiones y cuyo fin es garantizar la calidad.

Si se conceptualiza la evaluación como instrumento de gestión, es pertinente tomar en cuenta que el CONARE identifica algunos retos que debe enfrentar el conjunto de instituciones de educación superior para el periodo 2011-2015, entre ellos, uno vinculado con los esfuerzos evaluativos, en el cual se señala la necesidad de implementar estrategias que mejoren la rendición de cuentas y el reporte de logros a los diferentes sectores de la sociedad (CONARE, 2011, p. 35).

En el desafío que identifica el CONARE, se pone en evidencia la necesidad de reportar, a los diversos sectores sociales, los logros, que reflejan las responsabilidades de las universidades con la sociedad. De ahí que, como instrumento de gestión, los procesos evaluativos contribuyen a evidenciar el quehacer universitario de frente a la sociedad que le da sustento, es decir no solo en la gestión interna universitaria, sino en su proyección a la sociedad que le alberga.

Como herramienta para la toma de decisiones, la evaluación genera datos, opiniones y resultados que orientan las decisiones a lo interno de la institución con el propósito de garantizar la calidad.

El Plan de Desarrollo Institucional de la Universidad de Costa Rica 2008-2012 señala, dentro del Eje de Gestión Institucional, como factor clave la planificación y la evaluación, y ciertas acciones que contribuyen a la gestión; por ejemplo, la acción estratégica 3.1.2. sugiere que se implementen modelos de evaluación (rendición de cuentas y mejoramiento) para la toma de decisiones (UCR, OPLAU, 2008, p. 57). En esta acción estratégica se conciben 2 grandes prácticas que se sustentan en la evaluación: la rendición de cuentas y el mejoramiento continuo, las que, a su vez, coadyuvan a garantizar la calidad de esta Universidad.

En cuanto a la garantía de la calidad en las instituciones de educación superior, en los últimos años han tomado relevancia los procesos de autoevaluación, acreditación y reacreditación en el conjunto de las instituciones de educación superior, con sustento en 
contextos más amplios, nacionales e internacionales, con el fin de garantizar la calidad de las universidades.

Como señala Santos Guerra (1999, p. 41), existe una perspectiva de evaluación de la institución universitaria, cuya finalidad se dirige a una dimensión institucional, y se relaciona con lo siguiente: "Para que la Universidad sea una institución que aprende y no sólo una institución que enseña, necesita abrirse a las preguntas de la evaluación, recibir información rigurosa a que da lugar y comprometerse con un cambio consecuente".

En este sentido, parece oportuno desarrollar procesos de evaluación no solo dirigidos a conocer los resultados de los esfuerzos universitarios, sino a aquellos que se encaminen a sugerir cambios para el mejoramiento continuo. Más allá de la rendición de cuentas como perspectiva bastante utilizada desde los procesos de gerencia, de gestión y de administración de los recursos públicos, la noción del mejoramiento continuo conduce, más fehacientemente, a la continua revisión, al aprovechamiento de las experiencias contenidas en las organizaciones y a la responsabilidad de las instituciones públicas.

Desde el enfoque cualitativo de la evaluación, se sustentan también otras aplicaciones de los procesos, tales como: la participación, el aprendizaje, el conocimiento compartido y el empoderamiento de las personas involucradas. Dichos procesos representan el valor agregado que aporta la evaluación como disciplina de conocimiento.

Asimismo, bajo el enfoque de la evaluación persuasiva que señala Ernest House (1997), la evaluación se perfila como un acto de argumentación más que de demostración. Expone este autor, que no sería prudente solicitarle a la evaluación que emita conclusiones definitivas, pero sí podría llevar a proposiciones necesarias, convencer a un público concreto, en lugar de convencer de manera absoluta, y emitir tesis más o menos creíbles. Es en esta lógica argumentativa y persuasiva que se puede aumentar la comprensión apropiada de destinatarios concretos (pp. 70-71).

Se considera pertinente señalar el enfoque de la evaluación persuasiva que sostiene este autor para el análisis evaluativo desarrollado en la Vicerrectoría de Acción Social, en el tanto que se recurrió a un esfuerzo más de argumentación que de demostración ${ }^{10}$.

\footnotetext{
${ }^{10}$ Ernest House en su obra Evaluación, ética y poder sostiene que la evaluación persuade más que convence, argumenta más que demuestra y es más creíble que cierta (1997, p. 72).
} 


\subsection{La evaluación pluralista y el enfoque cualitativo}

Para aclarar el enfoque del estudio es pertinente señalar que se inscribe en una lógica de evaluación pluralista, en tanto esta última favorece una perspectiva más política:

La evaluación pluralista representa el reconocimiento de la naturaleza política de la evaluación. A diferencia de la concepción racionalista-científica, este modelo rechaza la idea de evaluación imparcial y objetiva de los resultados de un programa, para centrarse en la importancia de los valores y de las opiniones de la pluralidad de actores que tienen que ver con un programa. (Ballart, 1992, p. 153)

Ballart contribuye a destacar las siguientes características esenciales de la evaluación pluralista (p. 154):

- Se involucran los distintos actores e instancias participantes.

- Se responde a las necesidades de información del conjunto de actores.

- El carácter flexible y adaptativo reconoce la condición cambiante de los programas públicos.

- Como estrategia, se utiliza variedad de fuentes de datos, documentales, entrevistas, discusiones de grupo, observaciones y otros que contribuyen a conseguir familiaridad con el programa y sus actores.

- Se examina la experiencia concreta de los actores involucrados, sus opiniones y argumentaciones.

- La persona que evalúa desempeña un papel de facilitador y negociador.

Si se retoma la caracterización propuesta por Vargas (2001), con respecto a los enfoques de evaluación, según su pretensión de análisis de la realidad, este estudio se aproxima más a la perspectiva de comprensión de la realidad, en el cual:

(...) se niega la posibilidad del dualismo sujeto-objeto, considerando más bien la interacción entre lo observado y el observador. Se rechaza además la aproximación experimental, el control y la manipulación, y se busca la interacción y puesta en común de las construcciones individuales y grupales mediante procesos hermenéuticos que provoquen la interacción de los involucrados. (Vargas, 2001, p.40) 
Agrega esta autora que, desde esta orientación,

la persona que evalúa asume un papel facilitador que tiene como fin aclarar las reconstrucciones emergentes que surjan en el proceso, por parte de los diferentes grupos involucrados. La persona que evalúa es participante clave pues se encarga de reconstruir las realidades de las diferentes personas con respecto a lo evaluado. (Vargas, 2001, p. 40)

Desde el sustento particular de la evaluadora, una de las premisas fundamentales se refiere al carácter pedagógico del ejercicio de evaluar, en el sentido de que se provocan y se instalan nuevos aprendizajes para todas las personas involucradas. Las personas que hasta ese momento realizan la valoración del desempeño en los proyectos, poseen experiencias y conocimientos acumulados, relevantes para realimentar el ejercicio de análisis, mejora y actualización de los procesos.

Para la referencia a la evaluación cualitativa se retoman planteamientos de lan Shaw, entre ellos que este tipo de evaluación se realiza por medio de un contacto intenso en el campo, durante el cual la función del investigador es alcanzar una perspectiva general de la cultura y del contexto del objeto de estudio, así como la característica de que en lo particular se sitúa un tema general.

Este autor identifica como rasgo importante de la evaluación cualitativa, su carácter interpretativo, en el que la persona que la realiza puede conseguir los datos sobre las percepciones de los actores locales mediante un proceso de profunda cortesía, comprensión empática y suspensión de las percepciones propias sobre los temas de que se habla, en las que intervienen mucho el juicio y la persuasión mediante la razón (Shaw, 2003, pp. 30-32).

De las características reseñadas del enfoque cualitativo, se retoma la formulación de recomendaciones para las acciones presentes y para mejorar las acciones futuras, puesto que en la Universidad de Costa Rica, como institución pública, los procesos que se desarrollan en acción social deben contribuir a la excelencia y a las transformaciones que la sociedad requiere, según lo reza el Estatuto Orgánico.

Desde la tipología de evaluación, ${ }^{11}$ según el momento cuando se realiza, se trató de una evaluación de proceso, por lo que se procedió a la revisión de los mecanismos

\footnotetext{
${ }^{11}$ Para Niremberg, Brawerman y Ruiz, existe una distinción clásica entre evaluación ex ante y evaluación ex post que proviene de la tradición económica y se traslada a las ciencias sociales. Argumentan que se introdujo
} 
mediante los cuales se otorga una calificación por el desempeño de la persona, en uno o varios proyectos de acción social, durante la ejecución del proyecto.

La lógica formativa en la evaluación de proceso conlleva a la revisión de las acciones que se están ejecutando. En el caso del estudio evaluativo, se desarrolló durante el proceso de ejecución de las tareas evaluativas que realiza el personal asesor.

\section{METODOLOGÍA}

El análisis cualitativo desarrollado para la Vicerrectoría de Acción Social, se dirigió a realizar un estudio ${ }^{12}$ al proceso mediante el cual se otorga un determinado puntaje a la función que desarrollan las personas ejecutoras de los proyectos. De ahí que se sostiene que el proceso llevado a cabo resulta más congruente con una investigación evaluativa o un estudio evaluativo, que con una evaluación en sentido estricto.

El estudio, de carácter evaluativo, tuvo como punto de partida el conocimiento del instrumento, los criterios, las acciones vinculadas y la ponderación, acciones todas que realizan las personas asesoras de la Vicerrectoría, quienes son las responsables de aplicar el instrumento con el fin de calificar la acción social para efectos de Régimen Académico.

Se propició una discusión colectiva sobre el proceso y el instrumento, para obtener un consenso sobre la ponderación que cada persona asigna, según el rubro por valorar en el instrumento con el personal profesional de la Sección de Extensión Docente, por la preocupación permanente sobre la manera en que se aplica el instrumento vigente y la claridad que se requiere acerca de las repercusiones de dicha tarea.

Además, se consideró la cantidad de proyectos de dicha Sección, así como la complejidad y la diversidad de los proyectos que ahí se inscriben, complejidad derivada del variado alcance de los proyectos, sus propósitos, y las particularidades de su gestión financiera, por ejemplo, en los proyectos bajo la modalidad de vínculo externo remunerado.

también una diferenciación relacionada con el tipo de evaluación que se realiza durante la ejecución del proyecto, denominada de muy diversas maneras: de progreso o proceso, de gestión, concurrente, concomitante, intermedia, de operación, entre otras (Niremberg, Brawerman y Ruiz, 2003, pp. 53-55).

${ }^{12}$ La autora aclara que en el estudio desarrollado en la Vicerrectoría de Acción Social no se pretendió hacer la evaluación de un programa, un proyecto o una política institucional, sino llevar a cabo un estudio al proceso mediante el cual se otorga un determinado puntaje a la función que desarrollan las personas ejecutoras de los proyectos, ya que esa instancia universitaria tiene como tarea remitir esa calificación a la Comisión de Régimen Académico. 
Se recurre a la estrategia de los Grupos de discusión para facilitar el logro de consensos internos acerca de los criterios para ponderar cada ítem de manera estándar. La guía generadora para la discusión fue precisamente el instrumento vigente y el aporte de ejemplos concretos provino de programas o proyectos presentados para la referida calificación. En el primer esfuerzo de análisis del instrumento vigente se logró, a manera de interpretación de cada ítem, un instrumento "espejo" ${ }^{13}$ Esta herramienta resultó relevante y necesaria para ponerla en práctica mientras el estudio concluía y vale señalar que se constituyó en una guía práctica para resolver, al menos desde la Sección de Extensión Docente, las solicitudes de calificación que ingresan en cada ciclo lectivo a la Vicerrectoría.

De seguido, se realizan esfuerzos para la triangulación de los criterios con la colaboración del personal de las secciones de Trabajo Comunal y Extensión Cultural de la Vicerrectoría. El análisis documental recurrente resultó crucial para fundamentar el estudio de evaluación y configurar el producto terminal del proceso de análisis.

El proceso de consulta, de triangulación y de validación conduce a la elaboración de un instrumento nuevo que responda a las necesidades actuales de la Vicerrectoría, lo que exige la fundamentación desde algunos ejes principales y las dimensiones para calificar la acción social, así como los criterios e indicadores para otorgar determinado puntaje.

El esquema 1 resume las fases que se identifican en el estudio evaluativo

\footnotetext{
${ }^{13}$ Se definió como instrumento espejo un documento que resulta del análisis del instrumento vigente, que a manera de guía, ofrecía cada ítem la explicación de cómo se pondera.
} 


\section{Esquema 1}

Fases del estudio evaluativo

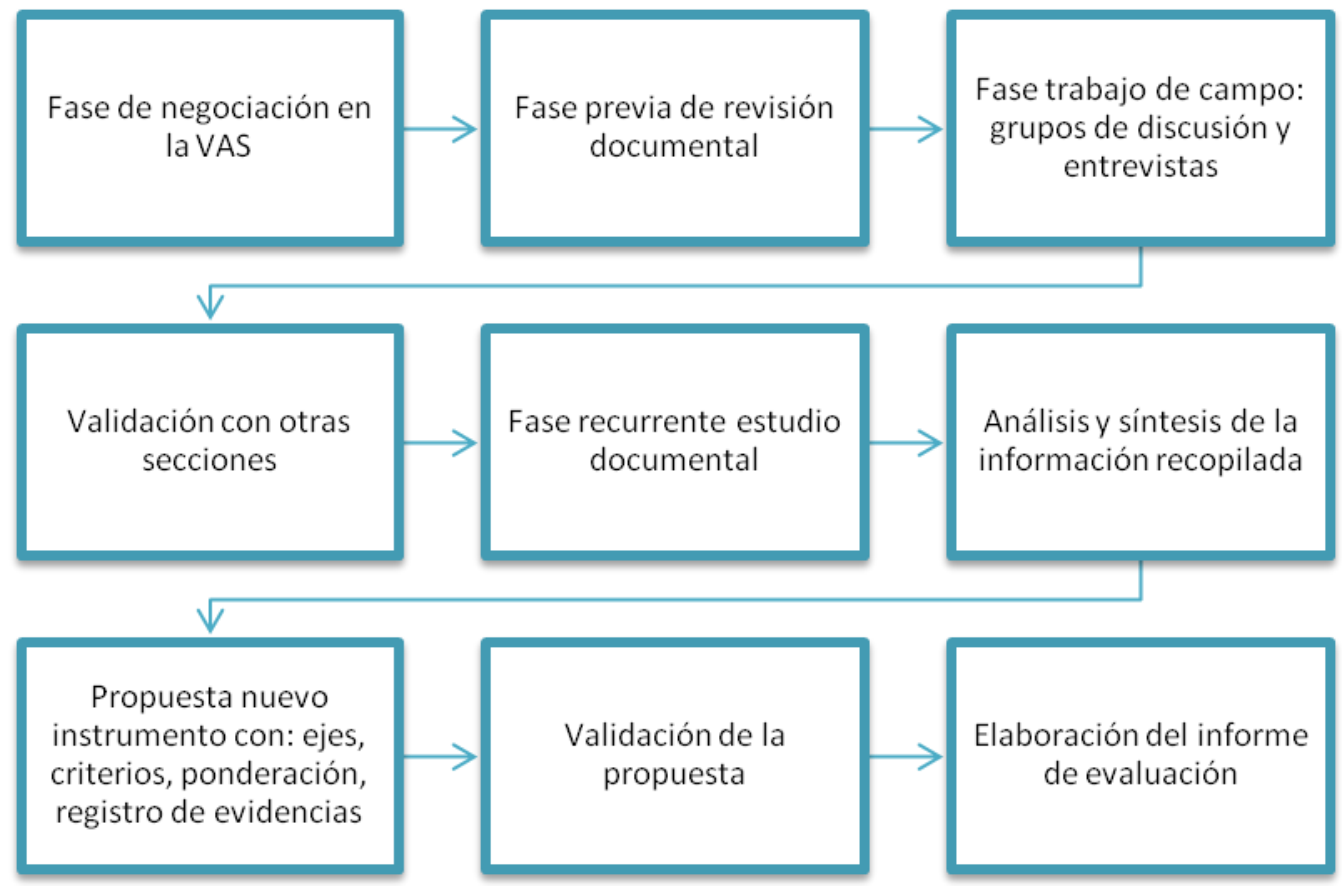

Fuente: elaboración propia

Como se observa, algunas de las fases son recurrentes, por ejemplo, el análisis documental llevado a cabo durante el estudio y las tareas de validación, que forman parte de un esfuerzo constante por diseñar una propuesta útil para atender la necesidad de contar con parámetros estándares al calificar la labor de acción social de quienes planifican y ejecutan programas y proyectos.

El siguiente apartado representa el esfuerzo de organizar los resultados, que también se constituye en un esfuerzo de integración, acomodamiento y orden sistemático, lógico y persuasivo del estudio, puesto que la investigación se asume como un proceso recurrente, dialéctico y riguroso.

\section{RESULTADOS Y ANÁLISIS}

La revisión de los criterios y parámetros que contiene el instrumento vigente para calificar las funciones de acción social, permitió generar un replanteamiento completo del instrumento. Tomando en consideración que la interpretación de cada criterio fue construida por quienes participan en el otorgamiento de la calificación en la Vicerrectoría, 
se vislumbró que el estudio de evaluación debería aportar criterios, ponderación, variables e indicadores para actualizar dicho instrumento. ${ }^{14}$

Se presenta en el siguiente acápite una propuesta de ejes y criterios de evaluación, con el fin de que sean tomados en cuenta para la actualización tanto del instrumento vigente, como del procedimiento y las implicaciones para el personal académico, de la evaluación que se realiza en las secciones internas de la Vicerrectoría de Acción Social.

\subsection{Ejes por evaluar en un instrumento actualizado}

A continuación se exponen los ejes generales para la evaluación de la acción social que desarrolla el personal docente universitario. Estos 4 ejes se sustentan en los lineamientos emanados del Consejo Nacional de Rectores (CONARE), en su documento Plan Nacional de la Educación Superior Universitaria Estatal 2006-2010, así como en las Políticas de la Universidad de Costa Rica para los años 2010-2014, emitidas por el Consejo Universitario.

De igual forma, se han utilizado para la fundamentación de estos ejes el Plan de Desarrollo Institucional de la Universidad de Costa Rica para el período 2008-2012, el documento Vinculación del Plan de Desarrollo Institucional 2008-2012 con las Políticas Institucionales 2008 y 2009, el documento Políticas institucionales y directrices operativas para los años 2010-2014.

Asimismo, se revisaron documentos de trabajo de la Vicerrectoría de Acción Social, como la Matriz para valoración de nuevas propuestas (UCR, VAS, s.f.) y el documento de trabajo elaborado en la Sección de Extensión Docente (documento espejo).

Se propone que la evaluación de las actividades de acción social se realice a partir de los siguientes ejes:

1. Vínculo con la sociedad: este es el componente central de la acción social y la extensión universitaria, pues es el mecanismo mediante el cual la Universidad ofrece su conocimiento a la sociedad que le alberga y le sustenta.

2. Poblaciones, ambientes y sectores vulnerables: este componente es fundamental en la actividad de acción social, pues se corrobora el interés y propósito universitario

\footnotetext{
${ }^{14}$ El análisis de la información recopilada en la Sección de Extensión Docente, la validación en las instancias internas de la Vicerrectoría, así como inquietudes documentadas desde algunas Comisiones de Acción Social y talleres específicos desarrollados desde la Vicerrectoría, confirmaron el requerimiento de plantear un instrumento con ejes, criterios y ponderaciones para calificar, de la manera más objetiva posible, las labores de acción social para efectos de puntaje en el Régimen Académico.
} 
de contribuir a las transformaciones que la sociedad requiere. En este eje se privilegian poblaciones, ambientes y sectores a los que la Universidad puede beneficiar.

3. Vínculo académico: se refiere a la articulación de las actividades sustantivas universitarias; este es otro de los componentes importantes por evaluar, pues se expresa el quehacer sustantivo de la institución. Dichas actividades consideradas en interrelación dinámica, al quehacer interno y a la misión institucional, mediante la organización de acciones sustantivas.

4. Gestión académico-administrativa: este eje se propone para considerar el desempeño de quienes organizan proyectos que se expresan mediante funciones de acción social. Los profesores y las profesoras desempeñan estas actividades de vínculo con la sociedad mediante la planificación, la ejecución y la evaluación de proyectos, programas y actividades concretas, por lo cual se plantean aquí algunos mecanismos para evaluar el desempeño.

Se presenta a continuación, en la Tabla 1, una breve fundamentación de cada uno de estos ejes. 
Tabla 1. Ejes que sustentan el instrumento de evaluación

\begin{tabular}{|c|c|}
\hline EJE 1. VíNCULO CON LA SOCIEDAD & $\begin{array}{c}\text { EJE 2: POBLACIONES, AMBIENTES Y SECTORES } \\
\text { VULNERABLES }\end{array}$ \\
\hline $\begin{array}{l}\text { Comprende múltiples expresiones del trabajo que } \\
\text { la Universidad de Costa Rica despliega para } \\
\text { contribuir con las transformaciones que la } \\
\text { sociedad requiere. } \\
\text { En este vínculo con la sociedad se articulan } \\
\text { esfuerzos para atender los desafíos de la } \\
\text { educación superior universitaria estatal, entre } \\
\text { ellos: } \\
\text { Generar mayor producción de conocimiento sobre } \\
\text { la realidad nacional y propuestas de acciones } \\
\text { plurales y pluralistas. } \\
\text { Fortalecer su vínculo con las comunidades, a fin } \\
\text { de obtener conocimiento directo sobre } \\
\text { necesidades sociales que luego puedan } \\
\text { convertirse en temas por atender mediante } \\
\text { actividades de investigación y desarrollo } \\
\text { (CONARE, 2005, p. 27) } \\
\text { En el documento PLANES, el CONARE define } \\
\text { objetivos y acciones concretas bajo un eje } \\
\text { estratégico que se denomina PERTINENCIA E } \\
\text { IMPACTO; para ello, se definen } 6 \text { componentes, de } \\
\text { los cuales se destacan: Vinculación con el } \\
\text { entorno, Articulación con el sistema educativo en } \\
\text { conjunto, Desarrollo regional, Responsabilidad } \\
\text { con el ambiente. }\end{array}$ & $\begin{array}{l}\text { Se refiere a la manera como se atienden } \\
\text { poblaciones, ambientes y sectores considerados } \\
\text { vulnerables, hacia los cuales la Universidad } \\
\text { despliega sus funciones de acción social. } \\
\text { Entre las políticas definidas en el CONARE que } \\
\text { tienen relación con poblaciones y ambientes } \\
\text { vulnerables, se pueden señalar las siguientes: } \\
\text { Las instituciones de educación superior } \\
\text { coadyuvarán al desarrollo integral de las } \\
\text { diferentes regiones del país, promoviendo el } \\
\text { trabajo de impacto significativo en los procesos de } \\
\text { desarrollo económico, social, cultural y ambiental. } \\
\text { Contribuirán con el desarrollo integral sostenible } \\
\text { de la sociedad, en un marco de solidaridad y } \\
\text { armonía entre el ser humano y la naturaleza } \\
\text { (CONARE, 2005, p. 30). } \\
\text { El vínculo con este eje se realiza en varias de las } \\
\text { políticas de la Universidad de Costa Rica, por } \\
\text { ejemplo: (1.1.2; } 1.1 .11 ; 5.2 .1) \\
\text { Promoverá el análisis, la discusión y la } \\
\text { participación en la solución de los problemas } \\
\text { nacionales, con el fin de plantear propuestas que } \\
\text { beneficien a la sociedad costarricense, con } \\
\text { énfasis en aquellos sectores más vulnerables y } \\
\text { excluidos socialmente. }\end{array}$ \\
\hline EJE & $\begin{array}{l}\text { ESTIÓN } \\
\text { MINISTRATIVA }\end{array}$ \\
\hline $\begin{array}{l}\text { Este eje comprende la integración de las } \\
\text { funciones sustantivas universitarias: docencia, } \\
\text { investigación y acción social. } \\
\text { Uno de los objetivos estratégicos definido por el } \\
\text { CONARE en el ámbito de Desarrollo Académico } \\
\text { señala: } \\
\text { Fundamentar el desarrollo de proyectos } \\
\text { académicos de las instituciones en el equilibrio e } \\
\text { integración de sus tres componentes principales: } \\
\text { docencia, investigación, extensión y acción social } \\
\text { (CONARE, p. 44) } \\
\text { El Desarrollo Académico se incorpora en el Plan } \\
\text { de Desarrollo Institucional de la Universidad de } \\
\text { Costa Rica con la siguiente definición: } \\
\text { Es la interrelación de las actividades de docencia, } \\
\text { investigación y acción social, orientadas a } \\
\text { fortalecer el quehacer académico con excelencia y } \\
\text { pertinencia, mediante la generación y la } \\
\text { socialización del conocimiento, la producción de } \\
\text { bienes y servicios científicos y tecnológicos para } \\
\text { contribuir con las transformaciones de la sociedad } \\
\text { (p. 43). }\end{array}$ & $\begin{array}{l}\text { Esta gestión comprende las dimensiones } \\
\text { administrativa y académica, que busca un } \\
\text { desempeño ágil, transparente y que contribuya al } \\
\text { mejoramiento de la calidad y la efectividad } \\
\text { institucional (CONARE, 2005, p. 32). } \\
\text { En el área de gestión, el CONARE establece } \\
\text { lineamientos estratégicos para las instituciones de } \\
\text { educación superior, entre ellos: } \\
\text { Promoverán la planificación de la educación } \\
\text { superior universitaria de manera tal que garantice } \\
\text { el cumplimiento de los objetivos básicos de } \\
\text { excelencia académica y del efectivo uso de los } \\
\text { recursos. } \\
\text { Promoverán la cultura de rendición social de } \\
\text { cuentas de todas las autoridades y funcionarios } \\
\text { universitarios, la cual constituirá una práctica } \\
\text { primordial que permitirá mostrar el resultado } \\
\text { global del quehacer institucional, así como el uso } \\
\text { transparente y eficiente de los recursos públicos. }\end{array}$ \\
\hline
\end{tabular}

Fuente: elaboración propia 


\subsection{Registro y consulta de las evidencias:}

Además del planteamiento de los ejes, se propone la recolección y verificación con las evidencias requeridas para realizar la evaluación de las funciones de acción social, de ahí que en la Tabla 2 se proponen algunos de los documentos necesarios para el registro de las evidencias:

Tabla 2. Documentos para recopilar evidencias, consultas y verificaciones

\section{Evidencias para consultas y verificaciones}

a. Informe de labores de cada proyecto; esto, por cuanto algunas personas son responsables de más de un proyecto de acción social.

b. Formulación de cada proyecto, con el fin de corroborar si, desde el inicio, el proyecto se planteó la incidencia en determinados aspectos.

c. Informe de ejecución presupuestaria

d. Reportes de visitas in situ o acompañamiento por parte de los asesores de la Sección, para nutrir la evaluación que se realiza. e. Minutas de reunión con responsables de proyectos, pues se realizan también sugerencias y correcciones para potenciar el proyecto, las que quedan recogidas en este tipo de documentos.

f. Registro de actividades de acción social, como capacitaciones, foros, conferencias y otros.

g. Cualquier otra documentación existente en la Sección de Extensión Docente, tales como: ponencias, artículos, lecciones aprendidas, y otra que contribuya a evaluar la incidencia de la acción social.

Fuente: elaboración propia

Este listado de evidencias contribuirá a emitir una ponderación más objetiva en cada uno de los criterios propuestos, al existir registro de la documentación consultada y las pruebas que sustentan la asignación de un puntaje. Esto, incluso, favorecerá la resolución de reclamos y apelaciones.

Es importante reiterar que la propuesta del nuevo instrumento para calificar la labor de acción social, se integra a partir de la definición de los ejes centrales en la documentación oficial, así como con la experiencia y los señalamientos ofrecidos por el personal técnico y profesional de la Sección de Extensión Docente.

Asimismo, se aclara que el planteamiento de preguntas orientadoras en cada criterio evaluativo pretende facilitar el ejercicio de valoración que la persona realiza para otorgar un determinado puntaje. En la Tabla 3 se plantea el eje por evaluar, los criterios y las preguntas que orientan la ponderación. 
Tabla 3. Propuesta de instrumento para evaluar las funciones de acción social

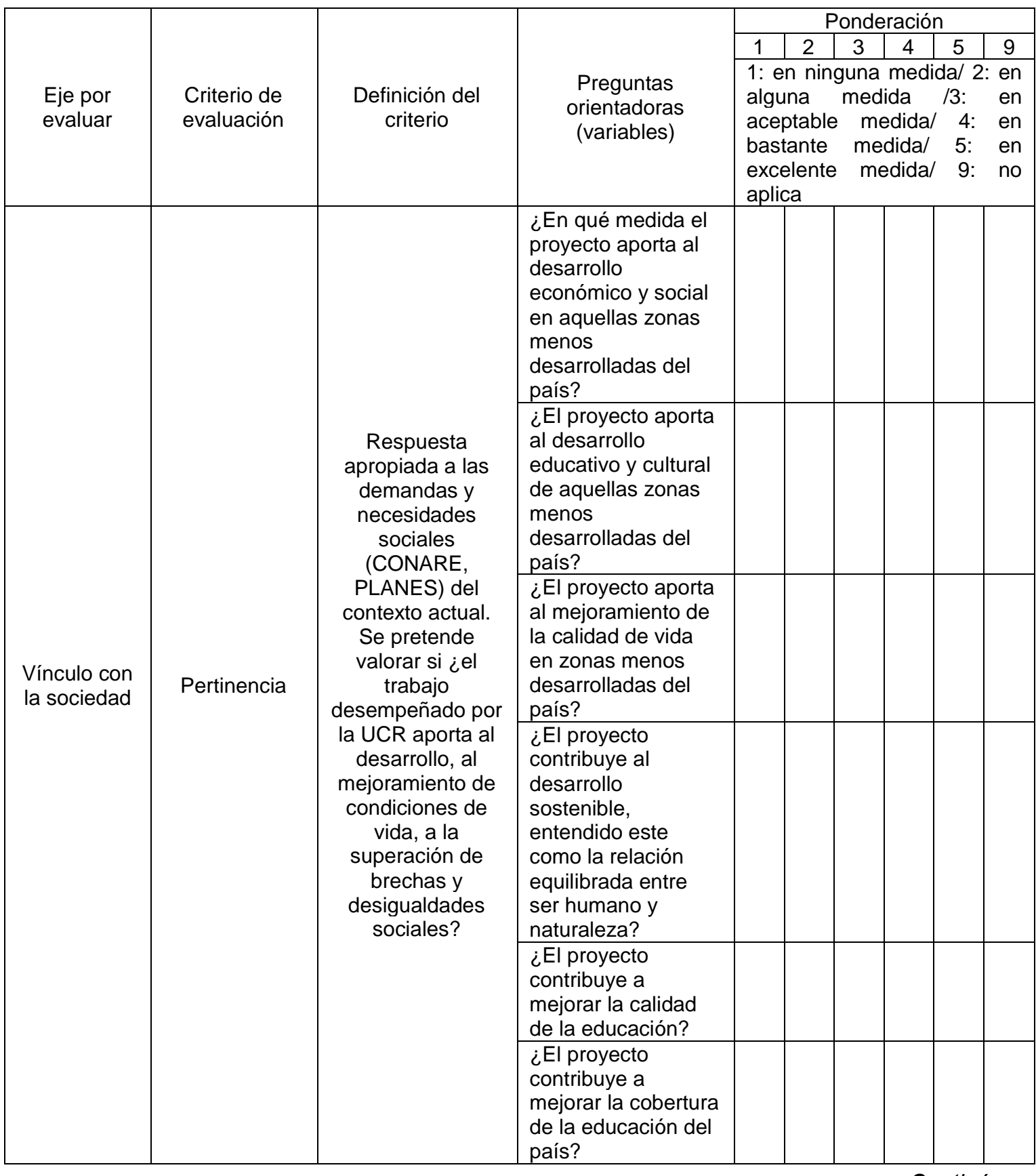

Continúa... 


\begin{tabular}{|c|c|c|c|c|c|c|c|c|c|}
\hline & & & & & & ond & ación & & \\
\hline & & & & 1 & 2 & 3 & 4 & 5 & 9 \\
\hline $\begin{array}{l}\text { Eje por } \\
\text { evaluar }\end{array}$ & $\begin{array}{l}\text { Criterio de } \\
\text { evaluación }\end{array}$ & $\begin{array}{l}\text { Definición del } \\
\text { criterio }\end{array}$ & $\begin{array}{l}\text { Preguntas } \\
\text { orientadoras } \\
\text { (variables) }\end{array}$ & $\begin{array}{l}1: \text { e } \\
\text { algu } \\
\text { ace } \\
\text { bas } \\
\text { exc } \\
\text { apli }\end{array}$ & $\begin{array}{l}\text { nin } \\
\text { la } \\
\text { abl } \\
\text { inte } \\
\text { ent } \\
\text { a }\end{array}$ & $\begin{array}{c}\text { muna } \\
\text { me } \\
\text { me } \\
\text { m }\end{array}$ & $\begin{array}{l}\text { medi } \\
\text { da } \\
\text { dida/ } \\
\text { ida/ } \\
\text { dida/ }\end{array}$ & $\begin{array}{l}\text { a/ } 2 \\
\text { 3: } \\
4: \\
5: \\
9:\end{array}$ & $\begin{array}{l}\text { en } \\
\text { en } \\
\text { en } \\
\text { en } \\
\text { no }\end{array}$ \\
\hline & & & $\begin{array}{l}\text { En la formulación } \\
\text { del proyecto ¿se } \\
\text { evidencia una } \\
\text { solicitud expresa } \\
\text { para que la } \\
\text { Universidad de } \\
\text { Costa Rica aporte a } \\
\text { la resolución de una } \\
\text { situación social } \\
\text { específica? }\end{array}$ & & & & & & \\
\hline & & $\begin{array}{l}\text { Aporte que brinda } \\
\text { la intervención } \\
\text { universitaria en } \\
\text { comunidades, } \\
\text { poblaciones, } \\
\text { instituciones, } \\
\text { grupos, etc. }\end{array}$ & $\begin{array}{l}\text { En la formulación } \\
\text { del proyecto ¿se } \\
\text { evidencia un } \\
\text { diagnóstico previo } \\
\text { de la situación o } \\
\text { condición que se } \\
\text { pretende resolver? }\end{array}$ & & & & & & \\
\hline $\begin{array}{l}\text { Vínculo con } \\
\text { la sociedad }\end{array}$ & Impacto & $\begin{array}{l}\text { (CONARE, } \\
\text { PLANES) Cambio } \\
\text { en la situación } \\
\text { social que se } \\
\text { atiende y que } \\
\text { puede ser } \\
\text { atribuido al }\end{array}$ & $\begin{array}{l}\text { En los resultados } \\
\text { concretos obtenidos } \\
\text { por el proyecto ¿se } \\
\text { revela un cambio } \\
\text { significativo en las } \\
\text { condiciones de vida } \\
\text { de las personas? }\end{array}$ & & & & & & \\
\hline & & $\begin{array}{l}\text { proyecto (VAS } \\
\text { documento de } \\
\text { trabajo). }\end{array}$ & $\begin{array}{l}\text { ¿La intervención de } \\
\text { la Universidad } \\
\text { generó cambios en } \\
\text { consideración a la } \\
\text { situación inicial de } \\
\text { la comunidad? }\end{array}$ & & & & & & \\
\hline & & & $\begin{array}{l}\text { ¿En qué medida } \\
\text { este proyecto } \\
\text { demuestra que la } \\
\text { Universidad invierte } \\
\text { el conocimiento } \\
\text { generado al servicio } \\
\text { de la sociedad? }\end{array}$ & & & & & & \\
\hline $\begin{array}{l}\text { SUBTOTAL } \\
\text { SOCIEDAD }\end{array}$ & MATORIA D & PUNTAJE SOBRE & VÍNCULO CON LA & Sub & & & & & \\
\hline (MÁXIMO DE & VTOS OBT & LES=55) & & & & & & & \\
\hline
\end{tabular}

Continúa... 


\begin{tabular}{|c|c|c|c|c|c|c|c|c|c|}
\hline \multirow[b]{3}{*}{$\begin{array}{l}\text { Eje por } \\
\text { evaluar }\end{array}$} & \multirow[b]{3}{*}{$\begin{array}{l}\text { Criterio de } \\
\text { evaluación }\end{array}$} & \multirow[b]{3}{*}{$\begin{array}{l}\text { Definición del } \\
\text { criterio }\end{array}$} & \multirow[b]{3}{*}{$\begin{array}{c}\text { Preguntas } \\
\text { orientadoras } \\
\text { (variables) }\end{array}$} & \multicolumn{6}{|c|}{ Ponderación } \\
\hline & & & & 1 & 2 & 3 & 4 & 5 & 9 \\
\hline & & & & \multicolumn{6}{|c|}{ 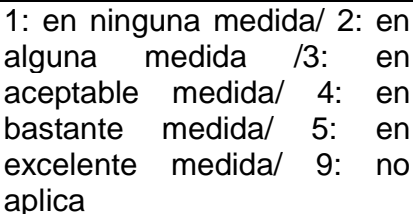 } \\
\hline \multirow{4}{*}{$\begin{array}{c}\text { Poblaciones } \\
\text { ambientes y } \\
\text { sectores } \\
\text { vulnerables }\end{array}$} & \multirow{4}{*}{ Relevancia } & $\begin{array}{c}\text { Trabajo } \\
\text { significativo que } \\
\text { realiza la } \\
\text { Universidad y que } \\
\text { permite mejorar la } \\
\text { condición de } \\
\text { distintas } \\
\text { poblaciones, } \\
\text { ambientes y } \\
\text { sectores. }\end{array}$ & $\begin{array}{l}\text { ¿En qué medida el } \\
\text { propósito y los } \\
\text { objetivos } \\
\text { planteados se } \\
\text { dirigen a atender } \\
\text { situaciones sociales } \\
\text { especificas en } \\
\text { poblaciones } \\
\text { vulnerables? }\end{array}$ & & & & & & \\
\hline & & \multirow{3}{*}{$\begin{array}{c}\text { En este trabajo } \\
\text { significativo que } \\
\text { despliega la } \\
\text { Universidad es } \\
\text { importante } \\
\text { considerar la } \\
\text { atención a la } \\
\text { vulnerabilidad en } \\
\text { sentido amplio de } \\
\text { poblaciones, } \\
\text { ambiente y } \\
\text { sectores, así } \\
\text { como la lejanía y } \\
\text { las condiciones de } \\
\text { acceso en que se } \\
\text { desenvuelve el } \\
\text { proyecto. }\end{array}$} & $\begin{array}{l}\text { ¿En qué medida los } \\
\text { objetivos se dirigen } \\
\text { a resolver } \\
\text { situaciones } \\
\text { especificas de } \\
\text { ambientes } \\
\text { vulnerables? }\end{array}$ & & & & & & \\
\hline & & & $\begin{array}{l}\text { ¿En qué medida el } \\
\text { propósito y los } \\
\text { objetivos se dirigen } \\
\text { a beneficiar a } \\
\text { sectores } \\
\text { vulnerables? }\end{array}$ & & & & & & \\
\hline & & & $\begin{array}{l}\text { ¿En qué medida el } \\
\text { proyecto incluye } \\
\text { estrategias y } \\
\text { acciones para } \\
\text { solventar } \\
\text { dificultades de } \\
\text { lejanía y de acceso } \\
\text { a las comunidades, } \\
\text { sectores y } \\
\text { ambientes } \\
\text { vulnerables? }\end{array}$ & & & & & & \\
\hline
\end{tabular}




\begin{tabular}{|c|c|c|c|c|c|c|c|c|c|}
\hline \multirow[b]{3}{*}{$\begin{array}{l}\text { Eje por } \\
\text { evaluar }\end{array}$} & \multirow[b]{3}{*}{$\begin{array}{l}\text { Criterio de } \\
\text { evaluación }\end{array}$} & \multirow[b]{3}{*}{$\begin{array}{l}\text { Definición del } \\
\text { criterio }\end{array}$} & \multirow[b]{3}{*}{$\begin{array}{c}\text { Preguntas } \\
\text { orientadoras } \\
\text { (variables) }\end{array}$} & \multicolumn{6}{|c|}{ Ponderación } \\
\hline & & & & 1 & 2 & 3 & 4 & 5 & 9 \\
\hline & & & & \multicolumn{6}{|c|}{ 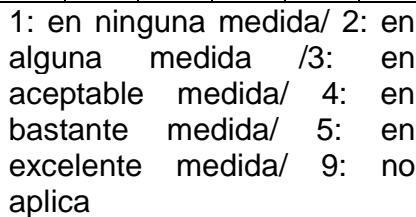 } \\
\hline \multirow{3}{*}{$\begin{array}{c}\text { Poblaciones } \\
\text { ambientes y } \\
\text { sectores } \\
\text { vulnerables }\end{array}$} & \multirow{3}{*}{ Relevancia } & \multirow{3}{*}{$\begin{array}{c}\text { Respuesta } \\
\text { apropiada a las } \\
\text { demandas y } \\
\text { necesidades } \\
\text { sociales de } \\
\text { poblaciones, } \\
\text { ambientes o } \\
\text { sectores } \\
\text { vulnerables }\end{array}$} & $\begin{array}{c}\text { Los logros } \\
\text { reportados } \\
\text { ¿evidencian una } \\
\text { respuesta } \\
\text { apropiada a las } \\
\text { demandas y } \\
\text { necesidades de las } \\
\text { personas que } \\
\text { constituyen la } \\
\text { población } \\
\text { vulnerable? }\end{array}$ & & & & & & \\
\hline & & & $\begin{array}{l}\text { Los logros } \\
\text { ¿evidencian una } \\
\text { respuesta } \\
\text { apropiada de la } \\
\text { Universidad a las } \\
\text { demandas y } \\
\text { necesidades de } \\
\text { determinados } \\
\text { sectores calificados } \\
\text { como vulnerables? }\end{array}$ & & & & & & \\
\hline & & & $\begin{array}{c}\text { Los resultados } \\
\text { obtenidos por el } \\
\text { proyecto ¿prevén la } \\
\text { sostenibilidad a } \\
\text { mediano y largo } \\
\text { plazo (en la zona, } \\
\text { en la comunidad, en } \\
\text { la población que se } \\
\text { atendió)? }\end{array}$ & & & & & & \\
\hline \multicolumn{4}{|c|}{$\begin{array}{l}\text { SUBTOTAL SUMATORIA DEL PUNTAJE SOBRE } \\
\text { AMBIENTES Y SECTORES VULNERABLES }\end{array}$} & \multirow{2}{*}{\multicolumn{6}{|c|}{ Subtotal: }} \\
\hline \multicolumn{4}{|c|}{ (MÁXIMO DE PUNTOS OBTENIBLES=35) } & & & & & & \\
\hline
\end{tabular}

Continúa... 


\begin{tabular}{|c|c|c|c|c|c|c|c|c|c|}
\hline \multirow[b]{3}{*}{$\begin{array}{l}\text { Eje por } \\
\text { evaluar }\end{array}$} & \multirow[b]{3}{*}{$\begin{array}{l}\text { Criterio de } \\
\text { evaluación }\end{array}$} & \multirow[b]{3}{*}{$\begin{array}{l}\text { Definición del } \\
\text { criterio }\end{array}$} & \multirow[b]{3}{*}{$\begin{array}{l}\text { Preguntas } \\
\text { orientadoras } \\
\text { (variables) }\end{array}$} & \multicolumn{6}{|c|}{ Ponderación } \\
\hline & & & & 1 & 2 & 3 & 4 & 5 & 9 \\
\hline & & & & \multicolumn{6}{|c|}{ 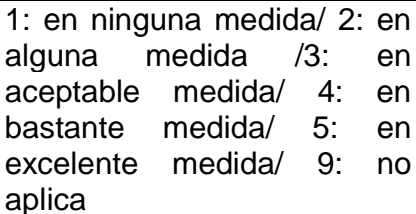 } \\
\hline \multirow{5}{*}{$\begin{array}{l}\text { Vínculo } \\
\text { académico }\end{array}$} & \multirow{5}{*}{$\begin{array}{l}\text { Vinculación } \\
\text { actividades } \\
\text { docencia- } \\
\text { investigación- } \\
\text { acción social }\end{array}$} & \multirow{5}{*}{$\begin{array}{c}\text { Se refiere al } \\
\text { desarrollo de } \\
\text { proyectos en } \\
\text { equilibrio e } \\
\text { integración de las } \\
\text { actividades } \\
\text { fundamentales } \\
\text { universitarias y el } \\
\text { beneficio mutuo } \\
\text { que de ellas se } \\
\text { derive. }\end{array}$} & $\begin{array}{l}\text { Con el desarrollo de } \\
\text { este proyecto ¿se } \\
\text { reporta articulación } \\
\text { con actividades } \\
\text { docentes a nivel de } \\
\text { grado? }\end{array}$ & & & & & & \\
\hline & & & $\begin{array}{l}\text { Con el desarrollo } \\
\text { del proyecto ¿se } \\
\text { aporta articulación } \\
\text { con actividades } \\
\text { docentes a nivel de } \\
\text { posgrado? }\end{array}$ & & & & & & \\
\hline & & & $\begin{array}{l}\text { El desarrollo del } \\
\text { proyecto ¿ha } \\
\text { permitido la } \\
\text { vinculación con } \\
\text { trabajos finales de } \\
\text { graduación? }\end{array}$ & & & & & & \\
\hline & & & $\begin{array}{l}\text { El desarrollo del } \\
\text { proyecto ¿ha } \\
\text { permitido } \\
\text { desarrollar vínculos } \\
\text { con proyectos o } \\
\text { actividades de } \\
\text { investigación? }\end{array}$ & & & & & & \\
\hline & & & $\begin{array}{l}\text { El desarrollo de } \\
\text { este proyecto ¿ha } \\
\text { permitido vincular } \\
\text { otros esfuerzos de } \\
\text { acción social } \\
\text { (programas, } \\
\text { proyectos, } \\
\text { actividades, cursos } \\
\text { libres, y otros)? }\end{array}$ & & & & & & \\
\hline
\end{tabular}

Continúa... 


\begin{tabular}{|c|c|c|c|c|c|c|c|c|c|}
\hline \multirow[b]{3}{*}{$\begin{array}{l}\text { Eje por } \\
\text { evaluar }\end{array}$} & \multirow[b]{3}{*}{$\begin{array}{l}\text { Criterio de } \\
\text { evaluación }\end{array}$} & \multirow[b]{3}{*}{$\begin{array}{l}\text { Definición del } \\
\text { criterio }\end{array}$} & \multirow[b]{3}{*}{$\begin{array}{c}\text { Preguntas } \\
\text { orientadoras } \\
\text { (variables) }\end{array}$} & \multicolumn{6}{|c|}{ Ponderación } \\
\hline & & & & 1 & 2 & 3 & 4 & 5 & 9 \\
\hline & & & & \multicolumn{6}{|c|}{$\begin{array}{l}\text { 1: en ninguna medida/ 2: } \\
\text { alguna medida /3: }\end{array}$} \\
\hline \multirow{6}{*}{$\begin{array}{c}\text { Vínculo } \\
\text { académico }\end{array}$} & \multirow[b]{2}{*}{$\begin{array}{l}\text { Vinculación } \\
\text { actividades } \\
\text { docencia- } \\
\text { investigación- } \\
\text { acción social }\end{array}$} & \multirow{2}{*}{$\begin{array}{l}\text { El desarrollo de } \\
\text { proyectos en } \\
\text { equilibrio e } \\
\text { integración de las } \\
\text { actividades } \\
\text { fundamentales } \\
\text { universitarias y el } \\
\text { beneficio mutuo } \\
\text { que de ellas se } \\
\text { derive }\end{array}$} & $\begin{array}{l}\text { El desarrollo de } \\
\text { este proyecto } \\
\text { ¿establece } \\
\text { relaciones con otras } \\
\text { instituciones de } \\
\text { educación superior } \\
\text { estatal? }\end{array}$ & & & & & & \\
\hline & & & $\begin{array}{l}\text { El desarrollo de } \\
\text { este proyecto } \\
\text { ¿logra establecer } \\
\text { relaciones con otras } \\
\text { instituciones, } \\
\text { organizaciones no } \\
\text { gubernamentales, } \\
\text { instituciones del } \\
\text { gobierno, entre } \\
\text { otros? }\end{array}$ & & & & & & \\
\hline & \multirow{4}{*}{$\begin{array}{l}\text { Producción } \\
\text { académica }\end{array}$} & \multirow{4}{*}{$\begin{array}{l}\text { Se consideran en } \\
\text { esta categoría: } \\
\text { libros, artículos de } \\
\text { revistas, obra } \\
\text { didáctica, obra } \\
\text { profesional o } \\
\text { artística. }\end{array}$} & $\begin{array}{l}\text { De la experiencia } \\
\text { en la ejecución del } \\
\text { proyecto ¿se } \\
\text { derivan } \\
\text { publicaciones de } \\
\text { libros? }\end{array}$ & & & & & & \\
\hline & & & $\begin{array}{l}\text { ¿La experiencia } \\
\text { desarrollada, los } \\
\text { resultados del } \\
\text { proyecto, las } \\
\text { lecciones u otro } \\
\text { aporte se publican } \\
\text { en revistas } \\
\text { académicas? }\end{array}$ & & & & & & \\
\hline & & & $\begin{array}{l}\text { El desarrollo de } \\
\text { este proyecto ¿ha } \\
\text { producido } \\
\text { materiales digitales, } \\
\text { audiovisuales u } \\
\text { otros? }\end{array}$ & & & & & & \\
\hline & & & $\begin{array}{l}\text { El desarrollo de } \\
\text { proyecto ¿ha } \\
\text { permitido la } \\
\text { producción de } \\
\text { material didáctico? }\end{array}$ & & & & & & \\
\hline
\end{tabular}

Continúa... 


\begin{tabular}{|c|c|c|c|c|c|c|c|c|c|}
\hline \multirow[b]{3}{*}{$\begin{array}{l}\text { Eje por } \\
\text { evaluar }\end{array}$} & \multirow[b]{3}{*}{$\begin{array}{l}\text { Criterio de } \\
\text { evaluación }\end{array}$} & \multirow[b]{3}{*}{$\begin{array}{l}\text { Definición del } \\
\text { criterio }\end{array}$} & \multirow[b]{3}{*}{$\begin{array}{c}\text { Preguntas } \\
\text { orientadoras } \\
\text { (variables) }\end{array}$} & \multicolumn{6}{|c|}{ Ponderación } \\
\hline & & & & 1 & 2 & 3 & 4 & 5 & 9 \\
\hline & & & & \multicolumn{6}{|c|}{$\begin{array}{l}\text { 1: en ninguna medida/ 2: en } \\
\text { alguna medida /3: } \\
\text { aceptable medida/ } 4: \text { en } \\
\text { bastante medida/ } 5: \text { en } \\
\text { excelente medida/ } 9: \text { no } \\
\text { aplica }\end{array}$} \\
\hline \multirow{6}{*}{$\begin{array}{c}\text { Vínculo } \\
\text { académico }\end{array}$} & \multirow{4}{*}{$\begin{array}{l}\text { Integración } \\
\text { disciplinaria }\end{array}$} & \multirow{4}{*}{$\begin{array}{l}\text { Se refiere a los } \\
\text { aportes } \\
\text { sustantivos } \\
\text { (integración y } \\
\text { contribución) de } \\
\text { varias disciplinas } \\
\text { en todo el ciclo } \\
\text { del proyecto: } \\
\text { desde la } \\
\text { formulación, la } \\
\text { ejecución y la } \\
\text { evaluación final. }\end{array}$} & $\begin{array}{l}\text { ¿Se evidencia el } \\
\text { trabajo de varias } \\
\text { disciplinas en la } \\
\text { formulación y } \\
\text { planteamiento del } \\
\text { proyecto? }\end{array}$ & & & & & & \\
\hline & & & $\begin{array}{l}\text { ¿Se evidencia el } \\
\text { trabajo de varias } \\
\text { disciplinas en la } \\
\text { ejecución y } \\
\text { seguimiento del } \\
\text { proyecto? }\end{array}$ & & & & & & \\
\hline & & & $\begin{array}{l}\text { ¿Se evidencia el } \\
\text { trabajo de varias } \\
\text { disciplinas en la } \\
\text { evaluación del } \\
\text { proceso del } \\
\text { proyecto? }\end{array}$ & & & & & & \\
\hline & & & $\begin{array}{l}\text { ¿Se evidencia el } \\
\text { trabajo de varias } \\
\text { disciplinas en la } \\
\text { evaluación de los } \\
\text { resultados del } \\
\text { proyecto? }\end{array}$ & & & & & & \\
\hline & \multirow{2}{*}{$\begin{array}{c}\text { Reconocimiento } \\
\text { nacional o } \\
\text { internacional }\end{array}$} & \multirow{2}{*}{$\begin{array}{l}\text { Se refiere a la } \\
\text { obtención de } \\
\text { premios, } \\
\text { distinciones y } \\
\text { reconocimientos } \\
\text { vinculados a las } \\
\text { actividades } \\
\text { desarrolladas en } \\
\text { los proyectos de } \\
\text { acción social. }\end{array}$} & $\begin{array}{l}\text { Los logros del } \\
\text { proyecto } \\
\text { ¿merecieron un } \\
\text { premio internacional } \\
\text { que evidencia la } \\
\text { importancia de la } \\
\text { acción social fuera } \\
\text { de nuestro país? }\end{array}$ & & & & & & \\
\hline & & & $\begin{array}{l}\text { Los logros del } \\
\text { proyecto } \\
\text { ¿merecieron un } \\
\text { premio a nivel } \\
\text { nacional que } \\
\text { evidencia el aporte } \\
\text { al país? }\end{array}$ & & & & & & \\
\hline
\end{tabular}

Continúa... 


\begin{tabular}{|c|c|c|c|c|c|c|c|c|c|}
\hline \multirow[b]{3}{*}{$\begin{array}{l}\text { Eje por } \\
\text { evaluar }\end{array}$} & \multirow[b]{3}{*}{$\begin{array}{l}\text { Criterio de } \\
\text { evaluación }\end{array}$} & \multirow[b]{3}{*}{$\begin{array}{l}\text { Definición del } \\
\text { criterio }\end{array}$} & \multirow[b]{3}{*}{$\begin{array}{l}\text { Preguntas } \\
\text { orientadoras } \\
\text { (variables) }\end{array}$} & \multicolumn{6}{|c|}{ Ponderación } \\
\hline & & & & 1 & 2 & 3 & 4 & 5 & 9 \\
\hline & & & & \multicolumn{6}{|c|}{ 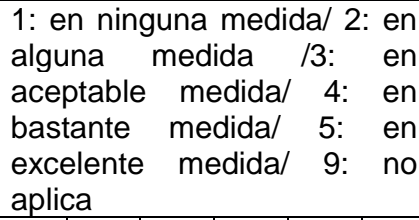 } \\
\hline \multirow{2}{*}{$\begin{array}{l}\text { Vínculo } \\
\text { académico }\end{array}$} & \multirow{2}{*}{$\begin{array}{l}\text { Integración } \\
\text { disciplinaria }\end{array}$} & \multirow{2}{*}{$\begin{array}{l}\text { Se refiere a los } \\
\text { aportes } \\
\text { sustantivos } \\
\text { (integración y } \\
\text { contribución) de } \\
\text { varias disciplinas } \\
\text { en todo el ciclo } \\
\text { del proyecto: } \\
\text { desde la } \\
\text { formulación, la } \\
\text { ejecución y la } \\
\text { evaluación final. }\end{array}$} & $\begin{array}{l}\text { ¿Se evidencia el } \\
\text { trabajo de varias } \\
\text { disciplinas en la } \\
\text { formulación y } \\
\text { planteamiento del } \\
\text { proyecto? }\end{array}$ & & & & & & \\
\hline & & & $\begin{array}{l}\text { ¿Se evidencia el } \\
\text { trabajo de varias } \\
\text { disciplinas en la } \\
\text { ejecución y } \\
\text { seguimiento del } \\
\text { proyecto? }\end{array}$ & & & & & & \\
\hline \multicolumn{4}{|c|}{$\begin{array}{l}\text { SUBTOTAL SUMATORIA DEL PUNTAJE SOBRE VÍNCULO ACADÉMICO } \\
\text { (MÁXIMO DE PUNTOS OBTENIBLES = 95) }\end{array}$} & \multicolumn{6}{|c|}{ Subtotal: } \\
\hline \multirow{3}{*}{$\begin{array}{c}\text { Gestión } \\
\text { académico- } \\
\text { administrativa }\end{array}$} & \multirow{3}{*}{$\begin{array}{l}\text { Rendición de } \\
\text { cuentas }\end{array}$} & \multirow{3}{*}{$\begin{array}{c}\text { Se refiere a la } \\
\text { divulgación de } \\
\text { resultados y } \\
\text { logros obtenidos } \\
\text { en los proyectos } \\
\text { de acción social, } \\
\text { limitaciones y } \\
\text { posibilidades de } \\
\text { mejora. }\end{array}$} & $\begin{array}{l}\text { En el informe del } \\
\text { proyecto ¿se da } \\
\text { cuenta de las } \\
\text { formas en que se } \\
\text { divulgan los } \\
\text { resultados en la } \\
\text { comunidad o grupo } \\
\text { participante, con el } \\
\text { sector o la } \\
\text { institución con que } \\
\text { trabajó el proyecto? }\end{array}$ & & & & & & \\
\hline & & & $\begin{array}{l}\text { En el informe final } \\
\text { ¿se reportan los } \\
\text { logros y las } \\
\text { opciones de mejora } \\
\text { para futuros } \\
\text { proyectos? }\end{array}$ & & & & & & \\
\hline & & & $\begin{array}{l}\text { En el informe del } \\
\text { proyecto ¿se da } \\
\text { cuenta de las } \\
\text { formas en que se } \\
\text { superaron las } \\
\text { limitaciones y por } \\
\text { ende las lecciones } \\
\text { aprendidas? }\end{array}$ & & & & & & \\
\hline
\end{tabular}

Continúa... 


\begin{tabular}{|c|c|c|c|c|c|c|c|c|c|}
\hline \multirow[b]{3}{*}{$\begin{array}{l}\text { Eje por } \\
\text { evaluar }\end{array}$} & \multirow[b]{3}{*}{$\begin{array}{l}\text { Criterio de } \\
\text { evaluación }\end{array}$} & \multirow[b]{3}{*}{$\begin{array}{l}\text { Definición del } \\
\text { criterio }\end{array}$} & \multirow[b]{3}{*}{$\begin{array}{l}\text { Preguntas } \\
\text { orientadoras } \\
\text { (variables) }\end{array}$} & \multicolumn{6}{|c|}{ Ponderación } \\
\hline & & & & 1 & 2 & 3 & 4 & 5 & 9 \\
\hline & & & & \multicolumn{6}{|c|}{  } \\
\hline \multirow{6}{*}{$\begin{array}{l}\text { Gestión } \\
\text { académico- } \\
\text { administra- } \\
\text { tiva }\end{array}$} & \multirow{6}{*}{$\begin{array}{l}\text { Rendición de } \\
\text { cuentas }\end{array}$} & \multirow{3}{*}{$\begin{array}{c}\text { Se refiere a la } \\
\text { divulgación de } \\
\text { resultados y } \\
\text { logros obtenidos } \\
\text { en los proyectos } \\
\text { de acción social, } \\
\text { limitaciones y } \\
\text { posibilidades de } \\
\text { mejora. }\end{array}$} & $\begin{array}{c}\text { El desarrollo del } \\
\text { proyecto ¿permitió } \\
\text { la participación en } \\
\text { foros, congresos, } \\
\text { eventos } \\
\text { académicos (incluye } \\
\text { actividades } \\
\text { artísticas) a escala } \\
\text { internacional? } \\
\end{array}$ & & & & & & \\
\hline & & & $\begin{array}{c}\text { Los logros del } \\
\text { proyecto ¿se } \\
\text { divulgan mediante } \\
\text { la participación en } \\
\text { foros, congresos, } \\
\text { eventos } \\
\text { académicos (incluye } \\
\text { actividades } \\
\text { artísticas) a escala } \\
\text { nacional? }\end{array}$ & & & & & & \\
\hline & & & $\begin{array}{c}\text { ¿Existe registro de } \\
\text { la participación en } \\
\text { actividades } \\
\text { divulgativas para } \\
\text { presentar } \\
\text { resultados del } \\
\text { proyecto (en ferias, } \\
\text { expos, u otras } \\
\text { actividades } \\
\text { universitarias)? }\end{array}$ & & & & & & \\
\hline & & \multirow{3}{*}{$\begin{array}{l}\text { Presentación y } \\
\text { calidad de los } \\
\text { informes }\end{array}$} & $\begin{array}{c}\text { ¿Se presenta el } \\
\text { informe final en los } \\
\text { plazos } \\
\text { establecidos? }\end{array}$ & & & & & & \\
\hline & & & $\begin{array}{l}\text { ¿El informe da } \\
\text { evidencia del } \\
\text { proceso del } \\
\text { proyecto? }\end{array}$ & & & & & & \\
\hline & & & $\begin{array}{l}\text { ¿El informe da } \\
\text { evidencia de los } \\
\text { aportes concretos } \\
\text { de la acción social } \\
\text { que desarrollo la } \\
\text { Universidad? }\end{array}$ & & & & & & \\
\hline
\end{tabular}

Continúa... 


\begin{tabular}{|c|c|c|c|c|c|c|c|c|c|}
\hline \multirow[b]{3}{*}{$\begin{array}{l}\text { Eje por } \\
\text { evaluar }\end{array}$} & \multirow[b]{3}{*}{$\begin{array}{l}\text { Criterio de } \\
\text { evaluación }\end{array}$} & \multirow[b]{3}{*}{$\begin{array}{l}\text { Definición del } \\
\text { criterio }\end{array}$} & \multirow[b]{3}{*}{$\begin{array}{c}\text { Preguntas } \\
\text { orientadoras } \\
\text { (variables) }\end{array}$} & \multicolumn{6}{|c|}{ Ponderación } \\
\hline & & & & 1 & 2 & 3 & 4 & 5 & 9 \\
\hline & & & & \multicolumn{6}{|c|}{  } \\
\hline \multirow{3}{*}{$\begin{array}{c}\text { Gestión } \\
\text { académico- } \\
\text { administrativa }\end{array}$} & \multirow{3}{*}{$\begin{array}{l}\text { Eficiencia en } \\
\text { la ejecución }\end{array}$} & $\begin{array}{l}\text { Se refiere a que } \\
\text { se cumplieron los } \\
\text { objetivos y las } \\
\text { metas e } \\
\text { indicadores } \\
\text { propuestos en el } \\
\text { proyecto en el } \\
\text { plazo estipulado. }\end{array}$ & $\begin{array}{l}\text { ¿El informe reporta } \\
\text { las dificultades y } \\
\text { limitaciones para el } \\
\text { cumplimiento de los } \\
\text { objetivos y las } \\
\text { metas planificadas? }\end{array}$ & & & & & & \\
\hline & & $\begin{array}{l}\text { El presupuesto } \\
\text { programado se } \\
\text { utilizó en las } \\
\text { actividades } \\
\text { planificadas y en } \\
\text { el plazo previsto } \\
\text { (no fue necesario } \\
\text { recurrir a la sub- } \\
\text { ejecución } \\
\text { presupuestaria } \\
\text { por parte de } \\
\text { autoridades de la } \\
\text { VAS). }\end{array}$ & $\begin{array}{l}\text { ¿La ejecución } \\
\text { presupuestaria del } \\
\text { proyecto se } \\
\text { presenta de manera } \\
\text { concreta y } \\
\text { evidencia una } \\
\text { buena utilización de } \\
\text { los recursos en el } \\
\text { tiempo establecido? }\end{array}$ & & & & & & \\
\hline & & $\begin{array}{c}\text { Los recursos } \\
\text { materiales y } \\
\text { financieros } \\
\text { disponibles } \\
\text { (materiales, } \\
\text { equipo, } \\
\text { infraestructura, } \\
\text { financiamiento y } \\
\text { otros) se utilizaron } \\
\text { de la mejor } \\
\text { manera posible. }\end{array}$ & $\begin{array}{l}\text { ¿El informe final } \\
\text { indica un uso } \\
\text { eficiente de los } \\
\text { recursos } \\
\text { disponibles } \\
\text { (materiales, equipo, } \\
\text { infraestructura)? }\end{array}$ & & & & & & \\
\hline \multicolumn{3}{|c|}{$\begin{array}{l}\text { SUBTOTAL SUMATORIA DEL } \\
\text { ACADÉMICO-ADMINISTRATIVA }\end{array}$} & SOBRE GESTIÓN & \multicolumn{6}{|c|}{ Subtotal: } \\
\hline \multicolumn{4}{|c|}{ (MÁXIMO DE PUNTOS OBTENIBLES = 65) } & & & & & & \\
\hline \multicolumn{10}{|c|}{ SUMATORIA TOTAL MÁXIMO PUNTAJE = 250} \\
\hline
\end{tabular}

Fuente: elaboración propia 


\section{CONCLUSIONES}

La complejidad de la estructura universitaria incide en la diversidad de los esfuerzos de acción social; por ende, los criterios para evaluar dichos esfuerzos deben ser lo suficientemente homogéneos para realizar una evaluación lo más objetiva posible.

En este sentido, se requiere fortalecer los procesos de evaluación, los instrumentos de calificación y las técnicas en la recopilación de datos, tanto para el seguimiento como para la evaluación final o evaluación de resultados. Además, debe existir coherencia y claridad en las distintas secciones de la Vicerrectoría de Acción Social, en lo referente a la evaluación de la formulación de los proyectos que presenta la población docente universitaria, con el fin de desarrollar proyectos de vínculo con la sociedad, así como dotar de mecanismos unificados a las unidades académicas para que, desde cada particularidad disciplinar, se adquieran criterios con el fin de que el aval que remiten las Comisiones de Acción Social, incluya el fundamento de la actividad que vincula a la Universidad con la sociedad.

Los ejes fundamentales para calificar la acción social como quehacer sustantivo, deben estar sustentados en las directrices generales para la educación superior, provenientes tanto del Consejo Nacional de Rectores como de la Universidad de Costa Rica. De la misma manera, las políticas universitarias que emanan del Consejo Universitario, dan sustento al accionar de la institución, por lo cual las directrices de la Vicerrectoría deben acoger los lineamientos derivados de esos instrumentos generales de gestión.

La Vicerrectoría de Acción Social ha desarrollado distintos esfuerzos de estrategias, directrices y lineamientos, que aparecen diseminados en las secciones y unidades que componen esta Vicerrectoría, de forma que el estudio evaluativo que se desarrolló fortalece la discusión para sustentar ejes generales, criterios específicos de evaluación, así como variables y preguntas por cotejar, vinculadas con las directrices, las políticas y los lineamientos que ha dictado esta instancia. Este análisis solo fue posible con la participación del personal técnico-profesional de la Vicerrectoría, especialmente de la Sección de Extensión Docente.

El propósito compartido se dirigió a modificar la lógica evaluativa como mecanismo de control, y propiciar un ejercicio evaluativo para mejorar y potenciar los logros, para recopilar los aprendizajes y reconocer los esfuerzos del vínculo Universidad - sociedad. 
La nueva propuesta es un insumo para una labor rigurosa que se sugiere que puede liderar la Vicerrectoría de Acción Social.

La calificación que se otorga de las funciones desempeñadas en acción social tiene repercusiones académicas y salariales; estas últimas con mayor peso para el personal en Régimen Académico. A pesar de que la situación del interinazgo en la Universidad de Costa Rica es un fenómeno estructural, desde la Vicerrectoría de Acción Social se podrían promover otros incentivos para que el personal interino participe en este tipo de actividades, tales como fondos específicos, fondos concursables, publicaciones especiales, pasantías, intercambios académicos, entre otros.

Para valorar las funciones desempeñadas en acción social, es importante el registro y las evidencias que fundamentan el otorgamiento de determinados puntajes. Las personas interesadas en obtener esta calificación deben contar con la información precisa acerca de los aspectos que se considerarán y evaluarán. Y las personas que realizan la calificación para someterla luego al proceso en la Comisión de Régimen Académico, requieren el apoyo instrumental para realizar el procedimiento de la forma más objetiva posible.

Un nuevo instrumental debe retomar la evaluación que efectúan las Comisiones de Acción Social o los Comités Científicos en el momento cuando se otorga el aval para la inscripción y desarrollo de un proyecto o iniciativa. La aprobación proveniente de cada disciplina y área de conocimiento es relevante, por cuanto en la Vicerrectoría no se puede tener evaluadores de todas las áreas y disciplinas. Por ello, conviene aprovechar la capacidad instalada y el conocimiento especializado en cada unidad académica y unidad de investigación, para contribuir a la evaluación de la acción social universitaria.

En congruencia con lo anterior, el instrumento de calificación no será suficientemente útil hasta que no exista consenso entre las secciones de la Vicerrectoría en cuanto a los estándares mínimos que se exigen para evaluar la labor de acción social. En otras palabras, el instrumento tendrá validez en la medida en que las personas asesoras de la Vicerrectoría analicen los criterios y las variables que contiene, y en tanto se proceda a un análisis riguroso no solo del instrumental, sino de los procedimientos, las personas responsables y las implicaciones para este quehacer universitario.

La propuesta del nuevo instrumento puede ser vista además como una excitativa a la apertura de una discusión mucho más amplia en la Universidad, como institución que se rige bajo los principios de excelencia, transparencia y mejoramiento continuo. 
Como corolario, desde la particularidad de la evaluación de programas y proyectos de desarrollo, el estudio evaluativo con enfoque pluralista, cualitativo y persuasivo, muestra una manera útil de acercarse a una realidad institucional, la cual resultó pertinente para quienes toman decisiones.

Se confirma la relevancia de los procesos de indagación cualitativa, con los cuales se pretendió dejar asentadas estrategias, habilidades y conocimientos para afrontar y mejorar el proceso en su conjunto.

El aprendizaje desde la disciplina de evaluación de programas y proyectos, no solo se remite al diseño y a la ejecución de una propuesta de investigación evaluativa, sino también a las destrezas y las habilidades para enfrentar diversos escenarios de negociación, facilitación y dirección de procesos, de sistematización de resultados, pero sobre todo, de persuasión desde la lógica evaluativa, la cual se concluye como relevante en los contextos institucionales cambiantes que exigen constantemente el acto de evaluar.

\section{Referencias}

Ballart, Xavier. (1992). ¿Cómo evaluar programas y servicios públicos? Aproximación sistemática y estudios de caso. Ministerio para las administraciones públicas. Madrid.

Consejo Nacional de Rectores (CONARE), Oficina de Planificación de la Educación Superior. (2005). Plan Nacional de la Educación Superior Universitaria Estatal 20062010. San José, Costa Rica: CONARE-OPES.

Consejo Nacional de Rectores (CONARE), Oficina de Planificación de la Educación Superior. (2011). Plan Nacional de la Educación Superior Universitaria Estatal 2011. 2015. San José, Costa Rica: CONARE-OPES.

House, Ernest. (1997). Evaluación, ética y poder. Madrid: Ediciones Morata.

Niremberg, Olga, Brawerman, Josette y Ruiz, Violeta. (2003). Evaluar para la transformación innovaciones en la evaluación de programas y proyectos sociales. Buenos Aires: Paidós.

Santos Guerra, Miguel. (1999). Sentido y finalidad de la evaluación de la Universidad. Revista Interuniversitaria de Formación del Profesorado, (34), 39-59.

Shaw, lan F. (2003). La evaluación cualitativa Introducción a los métodos cualitativos. Barcelona: Paidós.

Universidad de Costa Rica. (2001). Estatuto Orgánico de la Universidad de Costa Rica. San José, Costa Rica: Editorial de la Universidad de Costa Rica. 
Universidad de Costa Rica, Consejo Universitario. (1991). Regulaciones del Régimen Salarial Académico de la Universidad de Costa Rica. San José, Costa Rica: Editorial de la Universidad de Costa Rica.

Universidad de Costa Rica, Consejo Universitario. (2008). Reglamento de Régimen Académico y Servicio Docente. San José, Costa Rica: Editorial de la Universidad de Costa Rica.

Universidad de Costa Rica, Oficina de Planificación Universitaria (OPLAU). (2008). Plan de Desarrollo Institucional 2008-2012. San José, Costa Rica: Editorial de la Universidad de Costa Rica.

Vargas, Alicia. (2001). Enfoques evaluativos. Revista de Ciencias Sociales año II-III, número 93-92. Universidad de Costa Rica. 